\title{
Contação de histórias: resgate da memória e estimulo à imaginação
}

\author{
Shirlei Milene Torres* \\ Ana Lúcia Liberato Tettamanzy ${ }^{* *}$
}

\begin{abstract}
Resumo: A história contada através da oralidade Abstract: The story told through orality allows the permite a interação entre contador e ouvintes, já que o interaction between the teller and the listeners, since corpo e a voz propiciam vivências comunitárias, body and voice generate social life experiences, which perdidas na aceleração da vida moderna. Muitos are lost in the speed of modern life. Many educators educadores ainda não descobriram o quanto as histórias haven’t found out how much theses stories can help podem ajudá-los. O principal objetivo de contar uma them. The main goal of telling a story is to provide fun, história é divertir, estimulando a imaginação, mas uma stimulating the imagination, but a well-told story can história bem contada pode aumentar o interesse pela also increase the interest in class or lead to selfaula ou permitir a auto-identificação, favorecendo a identification, making the comprehension of unpleasant compreensão de situações desagradáveis e ajudando a situations easier and helping to solve conflicts. It resolver conflitos. Agrada a todos sem fazer distinção pleases everybody without distinctions of age, social de idade, classe social ou modo de vida. status or way of life.
\end{abstract}

Palavras-chave: memória; oralidade; cultura popular; Keywords: memory; orality; popular culture; stories; histórias; performance performance

Cantando Celebrai, oh Anciãos, A história da nossa raça. Que me seja dado ver em minha alma

O amor em todos os rostos.

E todos os espíritos que vieram antes,

O poder mágico que eles adquiriram, A tradição sagrada que me transmitiram

Para que a memória não desapareça. Oh Contador de Histórias, sede minha ponte

Para aqueles outros tempos.

Para que eu possa Caminhar em Beleza

Com o ritmo antigo e a antiga rima.

(Jamie Sams)

\footnotetext{
* Graduanda do Curso de Letras da UFRGS e do Curso de Teatro da UERGS, membro do Grupo Quem Conta um Conto - Contadores de Histórias desde 2005. shisv@msn.com.br

*** Doutora em Letras, professora de Literatura do Instituto de Letras da UFRGS e coordenadora do Grupo Quem Conta um Conto - Contadores de Histórias desde 2005. atettamanzy@ terra.com.br
} 
Antes da escrita, todo saber era transmitido oralmente. Deve-se a isto toda a importância dada à memória nas sociedades tradicionais, pois a memória era o único recurso para armazenar e transmitir o conhecimento às futuras gerações. $\mathrm{O}$ ato de contar histórias remete a este tempo em que o homem confiava na sua memória e nas suas experiências, resgatando qualidades tão necessárias ao desenvolvimento humano.

Ó mui talentoso Tote, enquanto um homem tem a capacidade de criar uma nova habilidade, outro a tem para julgar se ela será bênção ou maldição para seus usuários. Agora você, o pai das letras, com sua afeição, vê nelas o oposto do seu verdadeiro poder. Pois esta invenção fará com que aqueles que usam percam o saber em suas mentes, negligenciando suas memórias; visto que, através desta confiança nas letras que são externas e alheias à mente, eles perderão sua capacidade de recordar coisas dentro de si mesmos. Você não inventou um medicamento para fortalecer a memória, mas um substituto inferior para ela. Você está proporcionando aos seus alunos uma maneira de parecem sábios sem verdadeira sabedoria. (SCHOLES \& KELLOGG, 1977, p. 12)

Numa cultura oral, para se resolver efetivamente o problema de retenção do pensamento, já que não temos a presença da escrita, é necessário que ele surja através de padrões fortemente rítmicos, equilibrados, em repetições ou antíteses, em aliterações e assonâncias, em expressões epitéticas ou outras expressões formulares, em conjuntos temáticos padronizados. Afinal, "sabemos o que podemos recordar" (ONG, 1998, p. 44). Somente sabemos, realmente, aquilo que guardamos em nossa mente, o que é significativo. "As fórmulas (...) funcionam como apoios mnemônicos, como expressões fixas que circulam pelas bocas e pelos ouvidos de todos" (ONG, 1998, p. 45). Podemos dizer que nunca houve nenhuma sociedade que não tivesse a necessidade de fabular, de inventar-se ou de construir seus mitos e seu imaginário. Toda civilização que existiu contou.

Numa sociedade de imensa mecanização como a nossa, a contação de histórias faz refletir sobre qualidades esquecidas. A valorização do conhecimento transmitido pela oralidade recompõe o valor das experiências coletivas.

O ofício de contar histórias é remoto (...) e por ele se perpetua a literatura oral, comunicando de indivíduo a indivíduo e de povo a povo o que os homens, através das idades, têm selecionado da sua experiência como mais indispensável à vida. (MEIRELES, 1979, p. 41)

O hábito de ouvir histórias desde cedo ajuda na formação de identidades; no momento da contação, estabelece-se uma relação de troca entre contador e ouvintes, o que faz com que toda a bagagem cultural e afetiva destes ouvintes venha à tona, assim, levando-os a ser quem são. "Contar histórias é uma arte porque traz significações ao propor um diálogo entre as diferentes dimensões do ser" (BUSATTO, 2003, p. 10).

Somente me constituindo como sujeito, posso aspirar a igualdade na minha relação com o outro. E a arte cumpre um papel nesse sentido. Dizendo quem sou através do que faço, dialogo 
com os outros em um processo poroso que permite interpenetrações criativas, por meio de formas, sons, cores e palavras. (FARIA \& GARCIA, 2002, p. 121)

Muitos educadores ainda não descobriram o quanto as histórias podem ajudá-los; muitos continuam utilizando as histórias, quando utilizam, apenas para acalmar os educandos e não vêem as várias possibilidades de uma boa história. O principal objetivo em contar uma história é divertir, estimulando a imaginação, mas, quando bem contada, pode atingir outros objetivos, tais como: educar, instruir, conhecer melhor os interesses pessoais, desenvolver o raciocínio, ser ponto de partida para trabalhar algum conteúdo programático, assim podendo aumentar o interesse pela aula ou permitir a auto-identificação, favorecendo a compreensão de situações desagradáveis e ajudando a resolver conflitos. Agrada a todos sem fazer distinção de idade, classe social ou circunstância de vida.

Se observarmos o que diz Paulo Freire (1982) sobre leitura, podemos afirmar que é a partir da leitura de mundo que o ser humano aprende a ler os demais textos. Levando em consideração tal reflexão, a literatura oral, por expandir a leitura de mundo, é uma eficaz ferramenta para aguçar a curiosidade por outras artes e excitar a imaginação. Por isso, as salas de aula, antes de serem lugares onde existem livros com suas histórias presas em si, devem ser lugares onde as vozes correm vivas e entram em cabecinhas ávidas por imaginar.

\footnotetext{
Ninguém tem que ser obrigado a ler nada. Ler é um direito de cada cidadão, não é um dever. É alimento do espírito. Igualzinho a comida. Todo mundo precisa, todo mundo deve ter a sua disposição - de boa qualidade, variada, em quantidades que saciem a fome. Mas é um absurdo impingir um prato cheio pela goela abaixo de qualquer pessoa. Mesmo que se ache que o que enche aquele prato é a iguaria mais deliciosa do mundo. (MACHADO, 2002, p. 15)
}

Começar a ler deve ser uma iniciativa própria de cada um, precisamos apenas indicar os caminhos para que as pessoas despertem seu gosto pela leitura. “(...) entre as aquisições da infância, a riqueza das tradições, recebidas por via oral. Elas precederam os livros, e muitas vezes os substituíram. Em certos casos, elas mesmas foram o conteúdo desses livros." (MEIRELES, 1979, p. 42).

Um dos principais objetivos da escola é fazer com que os alunos gostem de ler. Mas, não podemos obrigá-los a isto, temos sim que encontrar formas de persuadir os alunos para que eles próprios busquem a leitura. Para isto, um caminho possível é o da contação de histórias, pois, como diz MEIRELES: "o gosto de ouvir é como o gosto de ler". Alguém que toma gosto em ouvir histórias, provavelmente, procurará lê-las também. Ou, até mesmo, chegará a escrevê-las, já que "o gosto de contar é idêntico ao de escrever e os primeiros narradores são os antepassados anônimos de todos os escritores" (1979, p. 42). A contação ajuda, principalmente, os alunos vindos de famílias analfabetas (incluem-se aqui também os 
analfabetos, chamados funcionais - sabem decodificar as letras, mas não sabem compreendêlas), já que estas crianças não seriam mais inseridas diretamente num discurso formal e científico, intitulado como oficial; partiriam do que lhes é conhecido.

Ao entrar em contato com um conto maravilhoso, uma quadrinha ou um dito da sabedoria popular, o estudante talvez pense: "Peraí! Meus pais conhecem isso! Isso eu já ouvi! Isso faz sentido para mim!” A partir daí, é perfeitamente possível imaginar que tal aluno volte para casa, conte o conto que aprendeu na escola e, no dia seguinte, traga outros contados pelo pai ou por algum parente. (AZEVEDO, 2004, p. 158)

Ao trabalhar com formas populares (parlendas, música, contos, etc) eles podem vir a reconhecer a cultura de sua própria família, ou melhor, podem perceber que sua gente também tem cultura.

(...) é a Literatura Tradicional a primeira a instalar-se na memória da criança. Ela representa o seu primeiro livro, antes mesmo da alfabetização, e o único, nos grupos sociais carecidos de letras. Por esse caminho, recebe a infância a visão do mundo sentido, antes de explicado; do mundo ainda em estado mágico. (MEIRELES, 1979, p. 66)

O romancista José Lins do Rego, por exemplo, ouvia muitas histórias orais tradicionais de uma ex-escrava, no engenho; isto fez com que seus livros fossem permeados por traços da oralidade dessas histórias que ouvia. Há também outros casos, como Ariano Suassuna e João Guimarães Rosa, grandes escritores de língua portuguesa, que beberam das histórias populares para compor suas obras. O próprio Guimarães diz em uma entrevista:

Nós, os homens do sertão, somos fabulistas por natureza (...) desde pequenos, estamos constantemente escutando as narrativas multicoloridas dos velhos, os contos e lendas (...) deste modo a gente se habitua, e narrar estórias corre por nossas veias e penetra em nosso corpo, em nossa alma, porque o sertão é a alma de seus homens. (ARROYO, 1984, p. 19)

Os contadores que se utilizam de histórias tradicionais o fazem por basear-se no seu vínculo com a vida concreta, como também com o sagrado. No momento em que ocorre a valorização das raízes, das religiões, das manifestações culturais, das expressões artísticas, etnia e raças, como também no compartilhamento da própria história, podemos ter a base sobre a qual se estruturam os processos identitários (cf. FARIA \& GARCIA, 2002, p. 126). Os contos possibilitam enxergar as diferenças culturais e constatar que a diversidade é saudável. Auxiliam “a expansão da nossa consciência ética e estética” (BUSATTO, 2003, p. 38).

Vemos nas histórias elementos identificadores do cotidiano do povo, mesmo quando são histórias de reis e cavaleiros, já que os temas encontrados no interior das histórias são universais. "A Literatura Tradicional apresenta esta particularidade: sendo diversa em cada país, é a mesma no mundo todo" (MEIRELES, 1979, p. 64). Contar histórias de origem na 
oralidade e na tradição popular restabelece um caminho que permite desenvolver um resgate da memória coletiva e do ato do ser humano de comunicar-se poeticamente. Além do que, nossa imaginação encontra um terreno fértil na literatura tradicional, já que os contos são curtos e econômicos, cabendo à imaginação completá-los. O conto da tradição popular, por ser econômico, se revela rico em imagens (cf. BUSATTO, 2003, p. 55), assim o ouvinte vai construindo todo o contexto da história conforme o que é sugerido pelo contador ao revelar as imagens do conto; imagens reveladas "a partir das formas, cores, sons e sensações presentes no seu corpo" (BUSATTO, 2003, p. 55). Essa é a grande magia das histórias, viajarmos para qualquer lugar, sem sairmos do lugar.

Contar histórias é arte performática, em que se tenta retransmitir os contos pelos meios nos quais surgiram, ou seja, através de voz, corpo e gesto. "A performance está presente. Você só pode me falar neste exato instante e eu não posso ouvir nada do passado" (ZUMTHOR, 1997, p. 61). É a própria criação do efêmero. “(...) performance designa um ato de comunicação como tal; refere-se a um momento tomado como presente. A palavra significa a presença concreta de participantes nesse ato de maneira imediata." (ZUMTHOR, 2000, p.59)

O contador vibra, o ouvinte estabiliza, integrando-se àquilo que é ele próprio. Então, é ele que vibra de corpo e alma. A noção de performance perpassa a idéia da presença de um corpo (cf. ZUMTHOR, 2000). A contação de histórias em performance permite a interação entre contador e ouvintes, o corpo e a voz propiciam vivências comunitárias, perdidas na aceleração da vida moderna.

\footnotetext{
O corpo é o peso sentido na experiência que faço (...). Meu corpo é a materialização daquilo que me é próprio, realidade vivida e que determina minha relação com o mundo (...). Na situação performancial, a presença corporal do ouvinte e do intérprete é presença plena, carregada de poderes sensoriais, simultaneamente, em vigília. (ZUMTHOR, 2000, p. 28 e 80)
}

Para quem está narrando (contando), o conto significa a realização simbólica de um desejo; o contador domina a platéia como se fosse um caçador abatendo sua presa, "vem daí o prazer em contar, prazer de dominação - associado ao sentimento de pegar aquele que escuta na sua armadilha" (ZUMTHOR, 1997, p. 55). “Antes de sensibilizar o ouvinte o conto precisa sensibilizar o contador" (BUSATTO, 2003, p. 55). É necessário que exista identificação entre conto e contador, para que este possa conduzir a narrativa da melhor forma. Cada contador coloca nas histórias um pouco de sua personalidade, priorizando passagens que, de alguma forma, dialogam mais com seu íntimo. É essa identificação entre o conto e seu contador que faz a diferença, pois dessa integração dependerá o sucesso da performance. É como se o conto 
escolhesse o contador e não o contrário. "É preciso ter tempo para sonhar os contos, isto é, ruminá-los interiormente, mas também é preciso ter a oportunidade de praticá-los, senão podem ser esquecidos" (SIMONSEN, 1987, p. 29). O contador deixa que a história mergulhe nele e só depois ele conta; primeiro se apropria da história para depois contá-la. "Ele precisa de tempo para deixar que a história mergulhe em seu próprio estoque de temas e fórmulas, tempo para "se emprenhar" da história. Quando recorda e reconta a história, em nenhum sentido literal da palavra ele "memorizou" (...)." (ONG, 1998, p. 73)

A performance aspira à qualidade de rito, pois transporta para outro lugar e para outro tempo. Através da performance consegue-se acelerar o movimento de identificação a ponto de provocar uma participação coletiva da platéia. No momento em que se consegue atingir a platéia, acontece uma experiência. É através do corpo que vivemos a experiência da performance. No momento em que estamos vivenciando a performance, estamos em processo de transformação. "O corpo é ao mesmo tempo o ponto de partida, o ponto de origem e o referente do discurso" (ZUNTHOR, 2000, p. 90).

Como nos fala BONDÍA (2002, p. 21): “A experiência é o que nos passa, o que nos acontece, o que nos toca. Não o que se passa, não o que acontece, ou o que toca". A performance só acontece quando contador e platéia permitem-se experimentar; quando ambos estão abertos à transformação. Isto porque "a performance modifica o conhecimento" (ZUNTHOR, 2000, p. 37), comunicando ela o marca.

É experiência aquilo que "nos passa", ou nos toca, ou que nos acontece, e ao nos passar nos forma e nos transforma. Somente o sujeito da experiência está, portanto, aberto à sua própria transformação (...). Se a experiência não é o que acontece, mas o que nos acontece, duas pessoas, ainda que enfrentem o mesmo acontecimento, não fazem a mesma experiência. (BONDÍA, 2002, p. 26-27)

O acontecimento é comum, como numa contação de histórias, por exemplo. A platéia ouve uma mesma história, mas o modo como cada pessoa experimentará será diferente. Quando há a performance, dá-se uma troca entre contador e ouvintes, dessa forma, também, cada vez que a história for contada, o contador contará de forma diferente, pois o ambiente, as pessoas e até mesmo o seu estado de espírito influenciarão em sua performance. Podemos dizer que, a cada contação, o contador conta uma história diferente, mesmo que aparentemente seja a mesma. "Cada performance nova coloca tudo em causa. A forma se percebe em performance, mas a cada performance ela se transmuda" (ZUMTHOR, 2000, p. 38-39). Durante a performance o ouvinte produz imagens; o virtual freqüenta o real; segundo ZUMTHOR (2000, p. 96) nossa percepção do real é freqüentada pelo conhecimento virtual resultante da acumulação da memória corporal. Uma história nunca vai provocar a mesma 
sensação nas diversas pessoas que a ouvem. "É a história da vida de cada um que determinará com que cores e com que música ela vai soar" (BUSATTO, 2003, p. 18).

Sempre que ouvimos uma história, ativamos nossa memória corporal, pois antes de recebermos a história de forma racional a recebemos através das sensações corporais. Toda contação de histórias vai ao encontro das ansiedades da platéia, já que cada ouvinte se identificará com a história, ou mesmo com parte da mesma, posto que dialoga com sua realidade atual. "A arte de contar histórias nos liga ao indizível e traz resposta às nossas inquietações" (BUSATTO, 2003, p. 9).

Ao utilizar-se a contação de histórias, todos saem ganhando, sejam os ouvintes, que serão instigados a imaginar e criar, seja o contador, que terá a oportunidade de recriar um ambiente de resgate da memória. E, ao pensarmos na escola, tanto os alunos como os professores terão uma aula muito mais atrativa e motivadora. Assim, quem mais sai ganhando é, na verdade, a sociedade, que receberá cidadãos mais criativos e capazes de conviver com a diversidade.

\section{Referências}

ARROYO, Leonardo. A Cultura Popular em Grande Sertão: Veredas. Rio de Janeiro: José Olympio, 1984.

AZEVEDO, Ricardo. Formas literárias populares e formação de leitores. In: BARBOSA, Márcia H. S.; RETTENMAIER, Miguel; RÖSING, Tânia M. K. (Org.). Leitura, identidade e patrimônio cultural. Passo Fundo: UPF, 2004.

BONDÍA, Jorge Larrosa. Notas sobre a experiência e o saber de experiência. In: Revista Brasileira de Educação. Rio de Janeiro, n. 19, p. 20-28, jan/fev/mar/abr. 2002.

BUSATTO, Cléo. Contar \& encantar: Pequenos segredos da narrativa. Rio de Janeiro: Vozes, 2003.

FARIA, Hamilton; GARCIA, Pedro. Arte e Identidade Cultural na Construção de um Mundo Solidário. In: _ O O reencantamento do mundo: arte e identidade cultural na construção de um mundo solidário. São Paulo: Polis, 2002.

FREIRE, Paulo. A importância do ato de ler. São Paulo: Cortez, 1982.

MACHADO, Ana Maria. Como e Por que ler os Clássicos Universais desde Cedo. Rio de Janeiro: Objetiva, 2002.

MEIRELES, Cecília. Problemas da Literatura Infantil. São Paulo: Summus, 1979. 
ONG, Walter. Oralidade e cultura escrita. Campinas: Papirus, 1998.

SAMS, Jamie. As cartas do Caminho Sagrado. Rio de Janeiro: Rocco, 2000.

SCHOLES, Robert; KELLOGG, Robert. A Natureza da Narrativa. São Paulo: MCGRawHill do Brasil, 1977.

ZUMTHOR, Paul. Introdução à poesia oral. São Paulo: Hucitec, 1997.

ZUMTHOR, Paul. Performance, Recepção, Leitura. São Paulo: EDUC, 2000. 